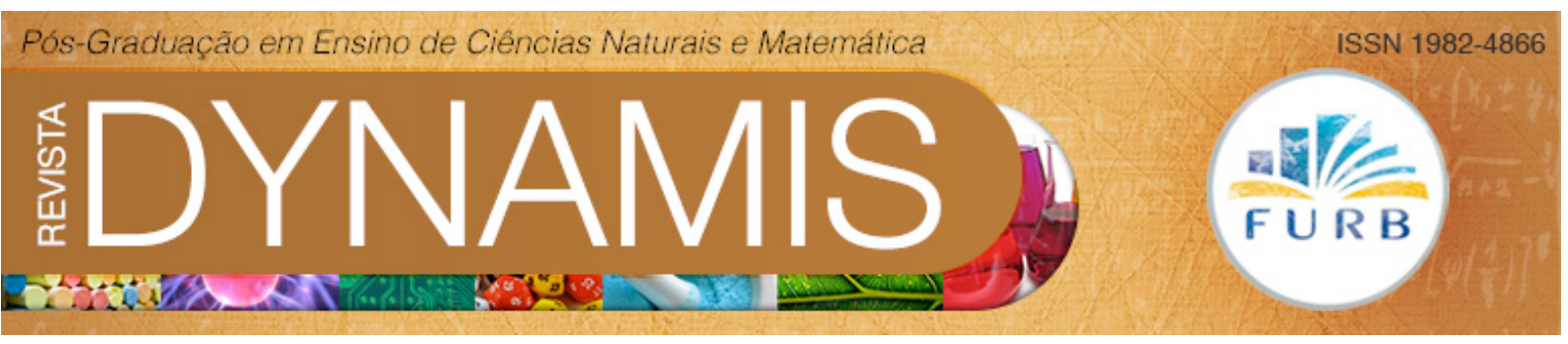

\title{
A Referencialização como Processo (e Método): uma Proposta para Avaliar a Formação de Egressos em Programas de Pós-Graduação da área de Ensino de Ciências
}

The Referencialization as Process (and Method): a Proposal to Evaluate the Egress Formation in Science Education' Postgraduate Courses

\section{Graziela Piccoli Richetti}

Programa de Pós-Graduação em Educação Científica e Tecnológica Universidade Federal de Santa Catarina grazirichetti@yahoo.com.br

José de Pinho Alves Filho

Programa de Pós-Graduação em Educação Científica e Tecnológica Universidade Federal de Santa Catarina jopinho@fsc.ufsc.br 


\section{Resumo}

A avaliação da pós-graduação brasileira, realizada pela CAPES, é imprescindível para apreciar a qualidade dos cursos. Todavia, existem críticas e restrições às suas limitações para mensurar a atividade formadora. Os cursos de mestrado e doutorado em Ensino de Ciências buscam aproximar a formação docente da prática pedagógica objetivando contribuir para a melhoria desse ensino em espaços de educação formal e não-formal. Apresentamos a dinâmica teórica da referencialização e uma proposta de percurso para a avaliação interna dos cursos de pósgraduação em Ensino de Ciências. Considerando os objetivos da formação e características, propomos um referencial de avaliação que ofereça um diagnóstico sobre o impacte dessa formação na prática pedagógica dos egressos. Propomos três dimensões de avaliação: curricular, epistemológica e educação científica e tecnológica, que podem ser complementadas em função do que se pretende avaliar, objetivando fornecer resultados destinados a melhoria da formação.

Palavras-chave: Referencialização; Avaliação; impacte.

\section{Abstract}

The evaluation of Brazilian post-graduate courses conducted by CAPES is essential to appreciate the quality of courses. However, there are criticisms and restrictions on its limitations to measure the formative activity. The masters and doctorate courses in Science Education attempt approach teacher education of pedagogical practices aiming contribute to the improvement of Science Teaching in formal and non-formal education. We present the theoretical dynamic of referencialization and a proposed route for the internal evaluation of postgraduate courses in Science Education. Considering the formative objectives and characteristics, we propose a referential that offers a diagnostic evaluation on the impact of this formation in pedagogical practice of its egresses. We propose three dimensions of evaluation: curriculum, epistemological and scientific and technological education, that can be complemented based on what is intended to evaluate, aiming provide results destined for improve formation.

Keywords: Referentialization; evaluation; impact. 


\title{
1. Introdução
}

A pós-graduação stricto sensu brasileira tem hoje respeito e reconhecimento internacional e é resultado, sem dúvida, do sistema de avaliação aplicado pela Coordenação de Aperfeiçoamento de Pessoal de Nível Superior (CAPES), instalada desde 1976, nos programas existentes. Claro está que restrições e críticas se fazem presentes às regras impostas pela CAPES, muitas delas justificadas pelas diferentes áreas, mas há de se entender sua complexidade, amplitude e importância e que a cada ano vem se aprimorando pela própria comunidade avaliadora (representantes de área, comissões de área e representantes de grande área). Vários são os trabalhos, nas mais diversas áreas e diferentes enfoques, que tratam sobre o processo de avaliação da CAPES, por exemplo, Spagnolo e Souza (2004), Horta e Moraes (2005), Souza e Macedo (2009), Saorim (2009) e Melo (2011). Entretanto, Souza e Macedo parecem ter captado o espírito do processo quando afirmam:

\begin{abstract}
A despeito das muitas críticas aos processos e aos resultados da avaliação, há consenso de que o fato da avaliação ser conduzida por pares [...] é positivo. Outro ponto sobre o qual há pouca controvérsia diz respeito à importância da avaliação para o crescimento planejado do sistema, evitando-se a proliferação de cursos/programas de pós-graduação que não atendam a uma qualidade mínima definida em consenso por critérios estabelecidos entre os pares. (Sousa \& Macedo, 2009, p. 256).
\end{abstract}

Ao assumir-se como aceito o posto pelos autores acima, não há como não aceitar que o processo de avaliação da CAPES se mostra eficaz aos seus objetivos, pois produz um conjunto de informações relativas ao sistema da pós-graduação brasileiro. Sua complexidade é inerente à diversificação de áreas, subáreas, etc. Todavia, suas informações de caráter macro acabam por oferecer subsídios que permitem (1) a tomada de decisões com relação ao fomento e ao planejamento do sistema de Ciência e Tecnologia (incluindo atendimento das necessidades nacionais e regionais), (2) o estabelecimento de padrões de qualidade visando à certificação dos programas que compõem o sistema, (3) o aprimoramento dos próprios programas, pela identificação de fragilidades e (4) a memória do sistema. Todo o esforço da comunidade acadêmica e da CAPES se mostram válidos e de grande importância para alcançar os objetivos elencados. Contudo, um dos questionamentos mais fortes na atualidade e que tem sido feito ao processo de avaliação da CAPES é à ênfase dada à produção científica em prejuízo das atividades formativas.

No caso específico da pesquisa em Ensino de Ciências (EC), a preocupação maior é formar pessoal qualificado para lidar com os problemas de ensino e aprendizagem próprios das Ciências, visando sua melhoria. Os primeiros cursos de pós-graduação nessa área surgem na década de 1970, época em que as primeiras teses e dissertações foram defendidas e os primeiros eventos nacionais fizeram parte de um conjunto de "ações voltadas para a melhoria do ensino de Ciências e Matemática no país" (NARDI, 2005, p. 17). Nas décadas de 1980 e 1990, a sociedade passou por um ciclo de mudanças culturais e comportamentais, originados pelo intenso avanço científico e tecnológico. Nesse sentido, os Programas de pós-graduação da área concentraram-se em suprir essa demanda ao propor objetivos mais direcionados à formação de mestres e doutores. Desde então, essa tendência tem acompanhado a estruturação e consolidação da área de EC e isso pode ser observado nas Propostas ${ }^{1}$ dos mais de cinquenta Programas de Pós-Graduação da área e, a título de exemplo, selecionamos os objetivos para a formação de pós-graduandos, extraídos de cinco Programas de Pós-Graduação em EC:

\footnotetext{
${ }^{1}$ Elaboradas pelos Programas de Pós-Graduação e enviadas à CAPES, disponíveis em http://conteudoweb.capes.gov.br/conteudoweb/CadernoAvaliacaoServlet?acao=pesquisaAno\&ano=2009.
} 
a) IES 1: O curso de mestrado profissional visa a melhoria da qualificação profissional de professores em exercício, tanto na educação básica como no ensino superior. Os cursos de mestrado e doutorado acadêmicos visam à formação de pesquisadores na área.

b) IES 2: A pós-graduação tem como objetivo completar e aperfeiçoar a formação de graduados em física, química e biologia, estimular a pesquisa e o ensino científico. Objetiva a produção de conhecimentos em educação científica para que seus alunos se tornem aptos a desenvolverem pesquisas com enfoques científico-conceituais, epistemológicos, entre outros.

c) IES 3: formar mestres e doutores capazes de elaborar e implementar projetos de pesquisa inovadores, fomentar a divulgação do conhecimento produzido e incentivar a cooperação entre pesquisadores.

d) IES 4: incentivar e enriquecer a produção e a socialização no campo da Educação Científica e Tecnológica e sua inserção em espaços de educação formal e não-formal.

e) IES 5: a pós-graduação tem como objetivos fomentar a produção intelectual e científica, oferecer embasamento e autonomia para o desenvolvimento de projetos que estimulem a disseminação da cultura científica e tecnológica e estimular esforços profissionais que contribuam para a melhoria da educação escolar e, consequentemente, da sociedade.

Uma leitura mais atenta desses objetivos evidencia preocupações comuns dos cursos, relacionadas à capacitação para o desenvolvimento de pesquisas em EC e à melhoria do ensino e aprendizagem das Ciências básicas, por meio da articulação entre conteúdos e assuntos de interesse social. Essas propostas corroboram com o exposto por Cachapuz (2011), que defende como estratégia formativa evitar o excesso de saberes acadêmicos (teóricos) e fortalecer a valorização das competências pessoais e profissionais dos professores, para favorecer a construção de novos saberes.

Atendendo à importância de se conhecer em que medida os objetivos para a formação pós-graduada estão sendo cumpridos e quais mudanças podem ser necessárias para otimizar a consecução dos mesmos, surge a necessidade de avaliar a qualidade dessa formação e seu impacte ao nível das práticas educativas dos egressos mestres e doutores. Ao levar-se em conta o crescimento do número de estudantes a frequentar, ou que venham a frequentar, cursos de pós-graduação no Brasil, torna ainda mais premente a avaliação da sua qualidade. Nosso entendimento de avaliação é de que esta pode, e deve, assumir sua natureza formativa e formadora, evitando uma postura meramente tecnicista de avaliação (Figari, 1996). Seu processo deve assentar num referencial que o sustente e oriente e, neste sentido, nosso objetivo é apresentar uma proposta de percurso e construção de um referencial para avaliar o impacte da formação oferecida pelos cursos de mestrado e doutorado de cursos de PósGraduação brasileiros voltados para o Ensino de Ciências.

\section{Fundamentação teórica}

Amparados por Withers (1995), assumimos uma concepção de avaliação inserida no "paradigma do melhoramento", ou seja, como um processo de natureza formativa e formadora, em que se articulam leituras, análises, instrumentos e ações, visando a identificação de funcionalidades, desvios, impactes e sugestões para melhorar a qualidade do objeto em avaliação. Hadji (1994, p. 178) complementa essa ideia ao estabelecer que o ato de 
avaliar é "um juízo através do qual nos pronunciamos sobre uma dada realidade, ao articularmos uma certa ideia ou representação daquilo que deveria ser, e um conjunto de dados" reais pertencentes à esta realidade e, por essa razão, o avaliador precisa de um quadro de referências "que lhe permita ler e dizer a realidade". Também em concordância com Figari (1996, p. 36), adotamos a referencialização como método investigativo para a avaliação dos dispositivos educativos, por meio da interrogação e do descerramento "de um sistema de coordenadas realizado em função do desígnio e do desenho que os atores dele podem traçar". $\mathrm{O}$ autor esclarece que um dispositivo "é, em si mesmo, 'educativo' quando desempenha um papel formador" e "que foi objeto de um projeto de aprendizagem ou de uma operação de avaliação" (Figari, 1996, p.30).

Visto que o conceito de avaliação é polissêmico e passível de diversas interpretações, duas questões essenciais demandam uma reflexão: 1) O que se pretende avaliar? e 2) Que referencial deve ser utilizado? A primeira questão requer, segundo Figari (1996, p. 36), uma descrição teórica que esclareça as finalidades, funções e especificidades do objeto de estudo. Já a segunda demanda uma resposta de caráter metodológico, pois é imperativo dispor de um quadro de referências elucidativo "da especificidade e dos efeitos de todo o dispositivo educativo". Yamamoto e Menandro (2004, p. 89) defendem "que uma avaliação pode questionar [...] a efetividade do seu funcionamento a julgar pelos resultados obtidos no período", o que corrobora com o fio condutor do processo de referencialização.

Nesse processo, dois conceitos constituem a base da avaliação: referente e referencial. $\mathrm{O}$ referente exerce o papel de norma, o que deve ser, aquilo que "pertence à ordem das representações de objetivos. Desempenha um papel instrumental na produção de um juízo de valor" (Barbier, 1985, p. 285). A primeira característica atribuída ao referente é a de retratar os sistemas de objetivos que conduzem o funcionamento das instituições de formação, permitindo que o avaliador compreenda "a natureza concreta das informações" obtidas "sobre o objeto avaliado" (Barbier, 1985, p. 73-74). Por sua vez, o conceito de referencial recebe a denotação de um sistema de referências que, em termos operacionais, representa um instrumento de medida orientador, que mediante um tratamento organizado de dados, favoreça a observação, e análise de um dispositivo educativo. Enquanto método, o referencial deve preconizar o tratamento simultâneo de dados originados da estrutura e das funções do dispositivo. Como produto de um processo científico, precisa "fornecer um eventual corpo de hipóteses que preveja a explicação dos resultados". É nessa etapa do percurso que a noção de referencial, com uma conotação estática, é corrigida para "referencialização", que indica a procura de um princípio que dê conta. (Figari, 1996, p. 57-58).

Figari (1996) assevera que a avaliação dos dispositivos educativos deve conter três dimensões: a) uma delimitação do contexto que designa as determinações e as origens, o que é induzido; b) uma elaboração individual e coletiva que indica o processo, a negociação e a elaboração, o que é construído; e c) um tratamento dos resultados e efeitos, que designa a atualização e a programação, o produzido. Essas três dimensões são inseparáveis, sendo que cada precisa ser corroborada pelas outras duas, em uma relação iterativa: "os dados 'induzidos' alimentam a 'construção' que leva ao aparecimento de uma 'produção', mas esta última constitui um fenômeno indutor de novos dados que, por seu turno, influenciam os outros pólos, etc." (Figari, 1996, p. 61).

É importante ressaltar que nosso estudo versa sobre uma avaliação de impacte e, nesse sentido, nosso entendimento sobre este conceito tem respaldo na perspectiva defendida pela National Education Research Forum (NERF). O conceito de impacte, associado ao contexto educacional, "refere-se à influência ou efeito que a pesquisa educacional exerce sobre a sua audiência" (NERF, 2000, p.1, tradução nossa). Mais concretamente, a avaliação do impacte 
dos cursos de pós-graduação em EC poderá demonstrar seus efeitos gradativos e temporais, a respeito do desempenho dos egressos mestres e doutores na sua atuação educativa. Este impacte pode ocorrer em três níveis. O primeiro, micro-impacte, refere-se à mudança nas ações profissionais de caráter do egresso; o segundo, meso-impacte, diz respeito à sua ação junto à sua instituição de trabalho e o terceiro, macro-impacte, abrange a sua participação na comunidade acadêmica e profissional mais ampla (Cruz et al., 2008, Pombo \& Costa, 2009). De posse desses esclarecimentos, passamos à discussão do percurso para a elaboração da proposta do modelo de avaliação.

\section{Metodologia}

Por meio da referencialização, Figari (1996) oferece o caminho metodológico para determinar os elementos do contexto da avaliação. Nesse sentido, assumimos os Programas de pós-graduação em EC como dispositivos educativos, e, como objeto de avaliação, o impacte da formação na prática pedagógica de seus egressos mestres e doutores. O percurso de construção do referencial deverá envolver: a) delimitação do contexto, em que poderão ser elencados documentos que regem a pós-graduação brasileira e a documentação no âmbito da Instituição de Origem do Programa de pós-graduação e b) elaboração de instrumentos para coleta de dados, por exemplo, tabelas de análise, questionários e entrevistas. Esses documentos deverão ser submetidos à análise de conteúdo, realizando-se uma leitura orientada dos mesmos, objetivando a compreensão do objeto de estudo. Concordamos com Oliveira et al (2003, p.16) quando afirmam que a análise de conteúdo "se configura como um procedimento confiável para atingir as linhas mestras de um texto". Nesse processo, poderá existir a necessidade de consultar os atores envolvidos com o funcionamento do dispositivo educativo e, por essa razão, poderão ser elaborados questionários e entrevistas para consultálos.

\section{Resultados}

A construção do referencial de avaliação deu origem a um quadro que contém o objeto da investigação e o sistema de referências. Na primeira parte são explicitados os referentes internos e externos, cujos aspectos considerados estão contidos na legislação da pósgraduação (brasileira e da Instituição). Apresentamos no Quadro 1 a construção desse sistema de referências: 
Quadro 1: Proposta de referencial de avaliação para Programas de Pós-Graduação em EC

\section{REFERENCIAL DE AVALIAÇ̃̃O DO PPGECT/UFSC}

Dimensões: Induzido, Construído e Produzido.

Operações: Delimitação do contexto, construção do processo e dos instrumentos para a avaliação do impacte do PPGECT/UFSC.

\begin{tabular}{|c|c|c|c|c|c|}
\hline \multicolumn{3}{|c|}{ Objeto } & \multirow{12}{*}{$\begin{array}{l}\text { Referencial } \\
\text { Do contexto nacional } \\
\text { (MEC e CAPES): } \\
\text { - Lei no 9.394/96, } \\
\text { estabelece as Diretrizes } \\
\text { e Bases da educação } \\
\text { nacional. } \\
\text { - Legislação dos } \\
\text { cursos de pós- } \\
\text { graduação stricto sensu } \\
\text { - Mestrado } \\
\text { Doutorado. } \\
\text { - III Plano Nacional de } \\
\text { Pós-Graduação (1986- } \\
\text { 1989). } \\
\text { - IV Plano Nacional de } \\
\text { Pós-Graduação (2005- } \\
\text { 2010). } \\
\text { - Avaliações trienais } \\
\text { da Pós-Graduação da } \\
\text { CAPES (2004 a 2010). }\end{array}$} & Aspectos a serem avaliados & Instrumentação \\
\hline \multirow{24}{*}{ 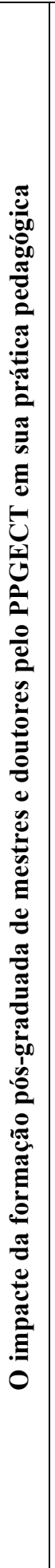 } & \multirow{11}{*}{\multicolumn{2}{|c|}{ 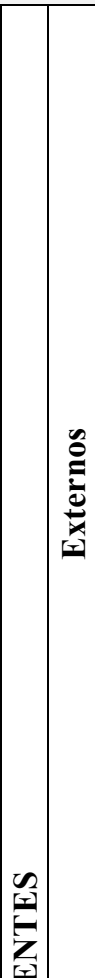 }} & & $\begin{array}{l}\text { Melhoria na estrutura dos programas de pós- } \\
\text { graduação, definição da proposta acadêmica e perfil } \\
\text { de atuação dos egressos. }\end{array}$ & \multirow{11}{*}{$\begin{array}{l}\text { - Análise } \\
\text { documental e de } \\
\text { conteúdo } \\
\\
\text { - Tabelas de } \\
\text { leitura }\end{array}$} \\
\hline & & & & Aumento da produção científica docente. & \\
\hline & & & & $\begin{array}{llll}\text { Aprimoramento nas definições e } & \text { no } \\
\text { desenvolvimento das atividades de pesquisa. } & \end{array}$ & \\
\hline & & & & $\begin{array}{l}\text { Cooperação internacional, intercâmbio entre alunos } \\
\text { e professores e apresentação de projetos de } \\
\text { captação de recursos junto às agências de fomento } \\
\text { internacionais. }\end{array}$ & \\
\hline & & & & Estrutura física adequada. & \\
\hline & & & & $\begin{array}{l}\text { Fortalecimento das bases científica, tecnológica e } \\
\text { de inovação. }\end{array}$ & \\
\hline & & & & $\begin{array}{l}\text { Estrutura curricular adequada aos estudantes e à } \\
\text { área de formação pós-graduada. }\end{array}$ & \\
\hline & & & & $\begin{array}{l}\text { Contribuição para a solução dos problemas sociais, } \\
\text { econômicos e tecnológicos. }\end{array}$ & \\
\hline & & & & $\begin{array}{l}\text { Aperfeiçoamento cultural, científico e profissional } \\
\text { (dos estudantes). }\end{array}$ & \\
\hline & & & & $\begin{array}{l}\text { Interação entre as atividades de pesquisa e pós- } \\
\text { graduação com o ensino de graduação. }\end{array}$ & \\
\hline & & & & $\begin{array}{l}\text { Cooperação interinstitucional, com intercâmbio } \\
\text { entre professores e alunos e realização de pesquisas } \\
\text { interdisciplinares e/ou multi-institucional. }\end{array}$ & \\
\hline & \multirow{13}{*}{ 胥 } & & \multirow{2}{*}{$\frac{\text { Do contexto local (IES }}{\frac{\text { e Programa de Pós- }}{\text { Graduação): }}}$} & $\begin{array}{l}\text { Estrutura curricular flexível } \\
\text { atividades acadêmicas). }\end{array}$ & \multirow{13}{*}{$\begin{array}{l}\text { - Análise } \\
\text { documental e de } \\
\text { conteúdo }\end{array}$} \\
\hline & & & & $\begin{array}{l}\text { Número mínimo de docentes permanentes e } \\
\text { colaboradores e qualificação do corpo docente. }\end{array}$ & \\
\hline & & \multirow{11}{*}{ 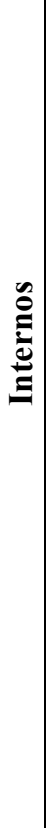 } & \multirow{11}{*}{$\begin{array}{l}\text { - Regimento ou } \\
\text { Regulamento do } \\
\text { Programa de Pós- } \\
\text { Graduação em EC. } \\
\text { - Normas regimentais } \\
\text { do Programa de Pós- } \\
\text { Graduação em EC. } \\
\text { - Cadernos } \\
\text { indicadores de } \\
\text { Programa de Pós- } \\
\text { Graduação em EC. } \\
\text { - Avaliação Trienal do } \\
\text { Programa de Pós- } \\
\text { Graduação em EC } \\
\text { (CAPES). }\end{array}$} & Recursos materiais. & \\
\hline & & & & $\begin{array}{l}\text { Organização e funcionamento acadêmico e } \\
\text { administrativo do Curso. }\end{array}$ & \\
\hline & & & & Objetivos de formação de mestres e doutores. & \\
\hline & & & & $\begin{array}{l}\text { Estrutura organizacional e curricular dos cursos de } \\
\text { Mestrado e Doutorado em EC (disciplinas, carga } \\
\text { horária, defesas, seleção, etc). }\end{array}$ & \\
\hline & & & & Participação em estágios docências. & \\
\hline & & & & Obtenção de créditos extra-curriculares. & \\
\hline & & & & Participação e apresentação de seminários. & \\
\hline & & & & $\begin{array}{l}\text { Distribuição das atividades de pesquisa e de } \\
\text { formação entre os docentes do programa. }\end{array}$ & \\
\hline & & & & $\begin{array}{l}\text { Coerência, consistência, abrangência e atualização } \\
\text { das áreas de concentração, linhas de pesquisa, } \\
\text { projetos em andamento e proposta curricular. }\end{array}$ & \\
\hline & & & & $\begin{array}{l}\text { Quantidade de teses e dissertações defendidas em } \\
\text { relação ao corpo docente permanente e à dimensão } \\
\text { do corpo discente. }\end{array}$ & \\
\hline & & & & $\begin{array}{l}\text { Distribuição das orientações das teses e dissertações } \\
\text { em relação aos docentes do programa. }\end{array}$ & \\
\hline
\end{tabular}




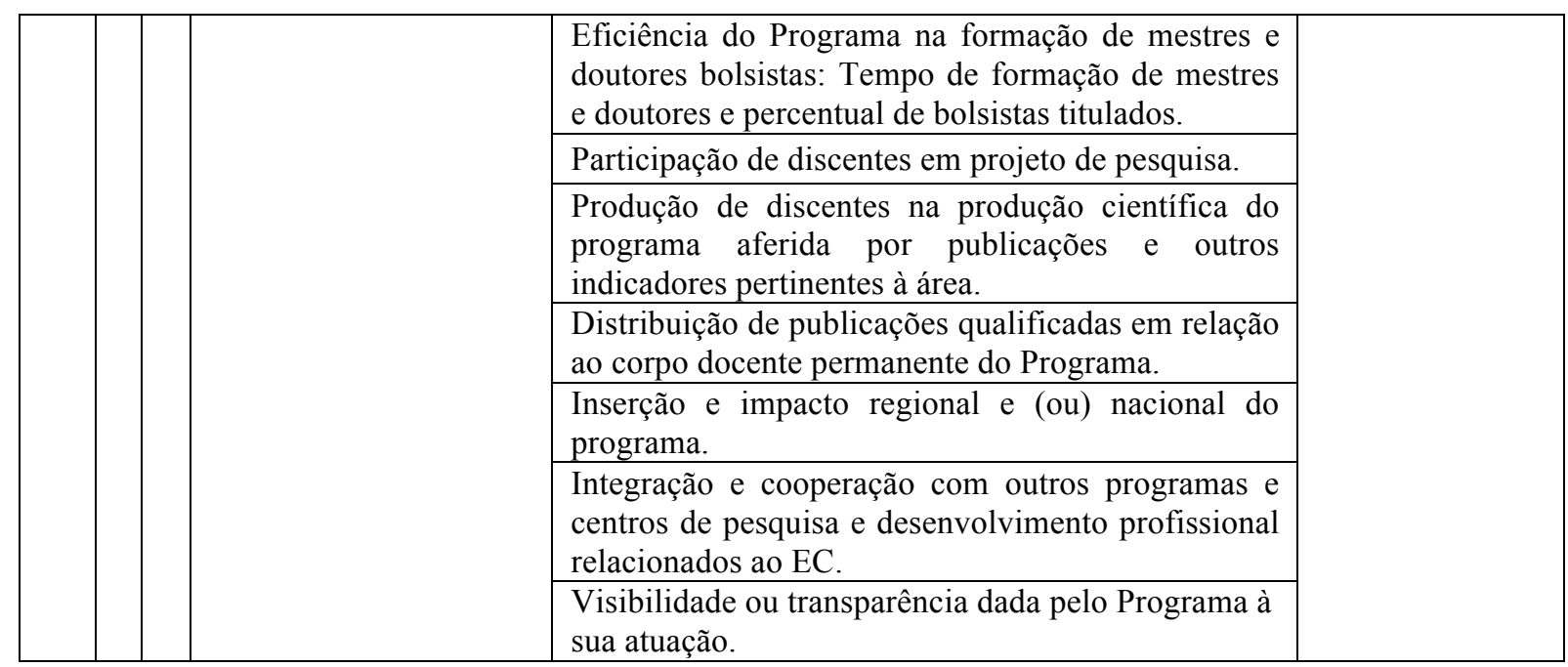

O Quadro 1 foi elaborado mediante uma "reconstrução abstrata e figurada da realidade" para favorecer a compreensão da dinâmica real do dispositivo educativo e compreender os dados numerosos e complexos derivados da sua avaliação. (Figari, 1996, p. 59). Utilizamos as três dimensões do dispositivo educativo - induzido, construído e produzido - para iniciar o processo com a delimitação do contexto, que pertence ao induzido. Fazem parte dessa dimensão os documentos elaborados no momento histórico em que a pós-graduação no Brasil precisava de uma definição. A título de exemplificação, podemos citar o Parecer CFE $n^{\circ}$ 977/65, de 3 de dezembro de 1965, que definiu os níveis e as finalidades da pós-graduação. Este e os demais documentos que normatizaram o Ensino Superior foram elaborados na década de 1960, e ajudaram a estruturar a pós-graduação e, portanto, designam as origens e pertencem ao induzido. Se considerarmos que esses documentos foram produzidos por fatores "indutores", eles também assumem o domínio do construído. Igualmente, esses documentos influenciaram a estruturação e normatização dos cursos existentes, bem como a criação de novos cursos, e por essa razão também fazem parte do produzido. As ações envolvidas no percurso de construção - análises, aplicação de instrumentos de coleta de dados, tratamento de dados - implicam em uma reflexão e farão parte da dimensão do construído. Além disso, o resultado dessas ações contribuirá para o produzido, que corresponderá ao efeito e ao resultado da formação. Esses resultados poderão, posteriormente, suscitar novas determinações para o induzido. É a essa iteratividade entre as dimensões do dispositivo educativo que Figari (1996) se refere e que deve perpassar todo o processo de avaliação.

O sistema de referências elencado para a construção do referencial foi constituído pelos documentos que normatizam os cursos de pós-graduação, divididos em dois grupos de referentes: a) externos: documentos nacionais, elaborados pelo MEC e pela CAPES, como a Lei de Diretrizes e Bases da Educação (LDB), os Planos Nacionais de Pós-Graduação (PNPG) e as Avaliações Trienais da CAPES; e b) internos: documentos próprios das Instituições de Ensino Superior, tais como resoluções, regimentos e normas internas dos cursos de pós-graduação. A análise documental e de conteúdo viabilizaram a etapa preliminar, onde buscamos conhecer o conteúdo desses documentos para compreender as linhas mestras dos cursos de pós-graduação. Como resultado, elaboramos uma lista de aspectos a serem considerados no processo de avaliação. Estes refletem as intenções, aquilo que é idealizado e devem auxiliar a contextualização e interpretação do objeto de estudo, para que o avaliador (ou grupo de avaliadores) tenha condições de elaborar "diagnósticos provisórios que se destinam a motivar o prosseguimento da procura sistemática de informações". (ALVES, 2004, p.96). Desta forma, os aspectos são uma parte importante do referente e favorecerão a definição das próximas ações da avaliação e a construção dos instrumentos destinados a 
investigar a formação oferecida pelos cursos de pós-graduação, nessa proposta, são neles inspirada. É importante que o Programa determine o período a ser avaliado, por exemplo, cinco anos, oito anos, dez anos, etc., e consulte os egressos por meio de questionário e nele, buscar suas impressões pessoais sobre o impacte da formação na sua atuação profissional atual.

Além de consultar os atores envolvidos, deriva da análise dos referentes uma proposta de quadro referencial com três dimensões de avaliação: curricular, epistemológica e educação científica e tecnológica. Para cada dimensão foram elencadas sub-dimensões, critérios e respectivos indicadores, que serão investigados com o auxílio de uma instrumentação específica. A priori, as três dimensões de avaliação propostas podem ser aplicadas a qualquer Programa de Pós-Graduação em EC, mas lembramos que outras dimensões podem ser requeridas para a avaliação e devem ser incluídas no quadro referencial. Cada dimensão contém subdimensões, critérios e respectivos indicadores, que serão investigados com o auxílio de uma instrumentação específica. As três dimensões formam um quadro único, mas para facilitar a leitura do texto e dos elementos do referencial, separamos um Quadro para cada dimensão, onde a dimensão curricular é apresentada no Quadro 2:

Quadro 2: Dimensão curricular da avaliação

\begin{tabular}{|c|c|c|c|c|}
\hline \multicolumn{5}{|c|}{ REFERENCIAL } \\
\hline Dimensão & Subdimensões & Critério & Indicadores & Instrumentação \\
\hline \multirow{9}{*}{ Curricular } & \multirow{2}{*}{$\begin{array}{l}\text { Conjunto das } \\
\text { disciplinas } \\
\text { obrigatórias } \\
\text { (estrutura } \\
\text { curricular) }\end{array}$} & \multirow[t]{2}{*}{$A D E Q U A C ̧ \tilde{A} O$} & $\begin{array}{l}\text { - Contém elementos à formação } \\
\text { dos discentes em processos } \\
\text { investigativos adequados a área } \\
\text { de educação. }\end{array}$ & \multirow{9}{*}{$\begin{array}{c}2 . \\
\text { Análise de } \\
\text { conteúdo: } \\
\text { - Planos de } \\
\text { ensino das } \\
\text { disciplinas } \\
\text { obrigatórias e } \\
\text { eletivas; } \\
\text { - Histórico } \\
\text { Escolar; } \\
\text { - Questões } \\
\text { abertas dos } \\
\text { questionários; } \\
\text { - Currículos } \\
\text { Lattes do corpo } \\
\text { docente e dos } \\
\text { egressos; } \\
\text { - Cadernos de } \\
\text { indicadores do } \\
\text { Programa de Pós- } \\
\text { Graduação. }\end{array}$} \\
\hline & & & $\begin{array}{l}\text { - Contém elementos à formação } \\
\text { em concepções educativas } \\
\text { modernas (construtivistas). }\end{array}$ & \\
\hline & \multirow{2}{*}{$\begin{array}{l}\text { Conjunto de } \\
\text { disciplinas } \\
\text { eletivas } \\
\text { (estrutura } \\
\text { curricular) }\end{array}$} & \multirow[t]{2}{*}{$A D E Q U A C ̧ \tilde{A} O$} & $\begin{array}{l}\text { - Contém elementos à formação } \\
\text { dos discentes em processos } \\
\text { investigativos adequados a área } \\
\text { de educação. }\end{array}$ & \\
\hline & & & $\begin{array}{l}\text { - Contém elementos à formação } \\
\text { em concepções educativas } \\
\text { modernas (construtivistas). }\end{array}$ & \\
\hline & \multirow{2}{*}{$\begin{array}{c}\text { Plano de } \\
\text { ensino da(s) } \\
\text { disciplina(s) }\end{array}$} & \multirow[t]{2}{*}{ PERTINÊNCIA } & $\begin{array}{l}\text { - Contém elementos à formação } \\
\text { dos discentes em processos } \\
\text { investigativos adequados a área } \\
\text { de educação. }\end{array}$ & \\
\hline & & & $\begin{array}{l}\text { - Contém elementos à formação } \\
\text { em concepções educativas } \\
\text { modernas (construtivistas). }\end{array}$ & \\
\hline & \multirow{3}{*}{$\begin{array}{l}\text { Interlocução } \\
\text { (diálogo) com } \\
\text { investigadores } \\
\text { externos ao } \\
\text { programa }\end{array}$} & \multirow{3}{*}{ EXISTENNCIA } & $\begin{array}{l}\text { - Existência de convênios } \\
\text { nacionais entre Programas de } \\
\text { PG com participação de } \\
\text { discentes. }\end{array}$ & \\
\hline & & & $\begin{array}{l}\text { - Existência de convênios de } \\
\text { cooperação internacional entre } \\
\text { o programa e instituições de } \\
\text { outros países com participação } \\
\text { de discentes. }\end{array}$ & \\
\hline & & & $\begin{array}{l}\text { - Participação dos discentes em } \\
\text { Seminários de Professores } \\
\text { convidados promovidos pelo } \\
\text { Programa. }\end{array}$ & \\
\hline
\end{tabular}




\begin{tabular}{|l|l|l|l|l|}
\hline & & $\begin{array}{l}\text { Participação dos discentes em } \\
\text { eventos científicos da área. }\end{array}$ & \\
\hline
\end{tabular}

Os quadros 2, 3 e 4, que contém as dimensões, foram elaborados em atendimento aos aspectos a serem considerados, listados no Quadro 1, e os objetivos da formação pósgraduada voltada para o EC. Na dimensão curricular, privilegiou-se uma análise organizacional e contextual do programa de pós-graduação, em que os objetivos propostos para a formação de mestres e doutores são evidenciados. Dados sobre as relações entre os conteúdos abordados nas componentes curriculares e as demais atividades dos cursos podem revelar aspectos favoráveis ou limitantes para a formação e posterior atividade educativa dos formados. Para investigar alguns critérios propostos, poderá ser necessário consultar egressos ou docentes atuais dos cursos por meio de questionário.

Para explorar a abordagem teórica da formação de modo mais transversal, propomos critérios e indicadores centrados nas disciplinas e na produção acadêmica discente, tal como explicitado no Quadro 3:

Quadro 3: Dimensão epistemológica da avaliação

\begin{tabular}{|c|c|c|c|c|}
\hline \multicolumn{5}{|c|}{ REFERENCIAL } \\
\hline Dimensão & Sub-dimensões & Critério & Indicadores & Instrumentação \\
\hline \multirow{5}{*}{ Epistemológica } & $\begin{array}{l}\text { Evidências de } \\
\text { vertentes } \\
\text { epistemológicas } \\
\text { no conjunto das } \\
\text { disciplinas }\end{array}$ & PRESENÇA & 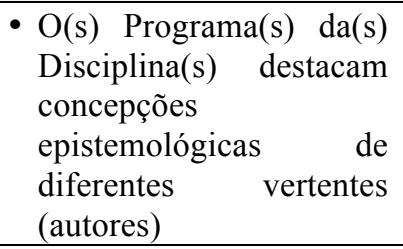 & \multirow{3}{*}{$\begin{array}{l}\text { - Questionários } \\
\text { com questões de } \\
\text { múltipla escolha } \\
\text { e questões } \\
\text { abertas; } \\
\\
\text { - Entrevistas com } \\
\text { uma amostra de } \\
\text { docentes e } \\
\text { egressos; }\end{array}$} \\
\hline & $\begin{array}{l}\text { Evidências de } \\
\text { vertentes } \\
\text { epistemológicas } \\
\text { no conjunto das } \\
\text { disciplinas na } \\
\text { interpretação da } \\
\text { ciência }\end{array}$ & EXISTENNCIA & $\begin{array}{l}\text { - O(s) Programa(s) } \\
\text { Disciplina(s) } \\
\text { umarabordam } \\
\text { epistemológica } \\
\text { ciênciar concepção } \\
\text { historicamente } \\
\text { neutra) }\end{array}$ & \\
\hline & $\begin{array}{c}\text { Evidências de } \\
\text { vertentes } \\
\text { epistemológicas } \\
\text { no conjunto das } \\
\text { disciplinas na } \\
\text { interpretação de } \\
\text { ensino de } \\
\text { ciência } \\
\end{array}$ & EXISTÊNCIA & $\begin{array}{lr}\text { - O(s) Programa(s) da(s) } \\
\text { Disciplina(s) abordam } \\
\text { uma } \quad \text { concepção } \\
\text { epistemológica } & \text { de } \\
\text { Ensino de ciência } \\
\text { comprometido r } \\
\text { reflexivo (construtivista) }\end{array}$ & \\
\hline & $\begin{array}{c}\text { Produção do } \\
\text { conhecimento } \\
\text { discente } \\
\text { referencia } \\
\text { vertentes } \\
\text { epistemológicas }\end{array}$ & EXPLICITAÇÃO & $\begin{array}{l}\text { - As teses e dissertações } \\
\text { explicitam a adoção de } \\
\text { vertente(s) } \\
\text { epistemológica(s) (autor) }\end{array}$ & $\begin{array}{l}\text { - Análise de } \\
\text { conteúdo das } \\
\text { entrevistas e } \\
\text { questões abertas } \\
\text { do questionário; }\end{array}$ \\
\hline & $\begin{array}{l}\text { Linhas de } \\
\text { Pesquisa do } \\
\text { Programa }\end{array}$ & COMPROMISSO & $\begin{array}{l}\text { - Compromissos com } \\
\text { categorias } \\
\text { epistemológicas nas } \\
\text { investigações e produção } \\
\text { do conhecimento. }\end{array}$ & $\begin{array}{l}\text { - Análise de } \\
\text { conteúdo das } \\
\text { teses e } \\
\text { dissertações. }\end{array}$ \\
\hline
\end{tabular}

Finalizando, no Quadro 4 propomos a dimensão da educação científica e tecnológica, em que as sub-dimensões, critérios e indicadores orientam a busca por dados sobre a análise operacional, ou seja, a prática pedagógica dos egressos mestres e doutores. Em função das 
dimensões e respectivos critérios e indicadores, poderão ser elaborados questionários e entrevistas, dirigidos aos atores envolvidos, como indicado nos Quadros 2, 3 e 4.

Quadro 4: Dimensão da educação científica e tecnológica da avaliação

\begin{tabular}{|c|c|c|c|c|}
\hline \multicolumn{5}{|c|}{ REFERENCIAL } \\
\hline Dimensão & Sub-dimensões & Critério & Indicadores & Instrumentação \\
\hline \multirow{9}{*}{$\begin{array}{l}\text { Educação } \\
\text { científica e } \\
\text { tecnológica }\end{array}$} & $\begin{array}{c}\text { Produção do } \\
\text { conhecimento dos } \\
\text { egressos }\end{array}$ & COMPROMISSO & $\begin{array}{lr}\text { - } \text { Comprometimento } & \text { dos } \\
\text { egressos com } & \mathrm{a} \\
\text { investigação } & \mathrm{e} \\
\text { construção } & \text { do } \\
\text { conhecimento em EC. }\end{array}$ & \multirow{9}{*}{$\begin{array}{c}\text { - Questionários } \\
\text { com questões de } \\
\text { múltipla escolha } \\
\text { e questões } \\
\text { abertas; } \\
\text { - Entrevistas com } \\
\text { uma amostra de } \\
\text { docentes e } \\
\text { egressos; } \\
\text { - Análise de } \\
\text { conteúdo das } \\
\text { entrevistas e } \\
\text { questões abertas } \\
\text { do questionário; }\end{array}$} \\
\hline & \multirow{3}{*}{$\begin{array}{l}\text { Incorporação do } \\
\text { conhecimento } \\
\text { adquirido na } \\
\text { formação na } \\
\text { prática } \\
\text { pedagógica dos } \\
\text { egressos }\end{array}$} & EXPLICITAÇ $\tilde{A} O$ & $\begin{array}{l}\text { - Comprometimento dos } \\
\text { egressos com a } \\
\text { investigação e produção } \\
\text { de conhecimento em } \\
\text { Didática em EC. }\end{array}$ & \\
\hline & & EXPLICITAÇ $\tilde{A} O$ & $\begin{array}{l}\text { - Proposições inovadoras e } \\
\text { reflexivas na sua prática } \\
\text { educativa. }\end{array}$ & \\
\hline & & RELEVÂNCIA & $\begin{array}{l}\text { - Alteração das estratégias } \\
\text { de ensino } \\
\text { aprendizagem }\end{array}$ & \\
\hline & $\begin{array}{c}\text { Disseminação do } \\
\text { conhecimento dos } \\
\text { egressos em sua } \\
\text { prática } \\
\text { pedagógica }\end{array}$ & \multirow{2}{*}{ COMPROMISSO } & \multirow{2}{*}{$\begin{array}{c}\text { - Comprometimento dos } \\
\text { egressos com a } \\
\text { disseminação do } \\
\text { conhecimento em EC. }\end{array}$} & \\
\hline & $\begin{array}{l}\text { Disseminação do } \\
\text { conhecimento dos } \\
\text { egressos através } \\
\text { da publicação de } \\
\text { trabalhos }\end{array}$ & & & \\
\hline & $\begin{array}{l}\text { Inserção e } \\
\text { participação em } \\
\text { projetos de } \\
\text { pesquisa }\end{array}$ & INOVAÇÃO & $\begin{array}{l}\text { - Proposições inovadoras } \\
\text { na prática educativa do } \\
\text { EC }\end{array}$ & \\
\hline & $\begin{array}{l}\text { Divulgação do } \\
\text { conhecimento dos } \\
\text { egressos em } \\
\text { situações não } \\
\text { formais } \\
\text { (Palestras/seminár } \\
\text { ios) }\end{array}$ & DIVULGAÇÃO & $\begin{array}{l}\text { - Egressos engajados na } \\
\text { inclusão do EC em todos } \\
\text { os espaços da educação } \\
\text { formal e não-formal. }\end{array}$ & \\
\hline & $\begin{array}{l}\text { Mantém relações } \\
\text { profissionais e } \\
\text { acadêmicas com o } \\
\text { Programa }\end{array}$ & PRESERVAÇÃO & - Vínculo com o Programa & \\
\hline
\end{tabular}

É importante ressalvar que outras dimensões podem emergir da análise de conteúdo dos referentes externos e internos ou dos dados coletados por meio dos questionários e, consequentemente, surgir a necessidade da realização de entrevistas semi-estruturadas a uma amostra de atores envolvidos com o dispositivo educativo sob avaliação. A proposta desse quadro de referências tem como objetivo principal conhecer e avaliar o funcionamento operacional e científico do Programa, que deverá envolver a estrutura curricular dos cursos oferecidos, as linhas e grupos de pesquisa, a produção discente e docente em um determinado período de tempo e a representatividade do Programa de Pós-graduação no cenário brasileiro. 
Além disso, a análise dos documentos oficiais Federais e locais, bem como a análise do currículo Lattes dos egressos e docentes compreendem um conjunto de dados que constituem um sistema "de referências já constituídos" e a eles poderão ser atribuídos diferentes sentidos, em função do que se deseja investigar. Em outras palavras, esse conjunto de dados deverá fornecer elementos empíricos para avaliar a qualidade da formação e o nível do seu impacte na prática educativa dos egressos.

\section{Conclusões}

Este trabalho é parte da pesquisa que está sendo desenvolvida para a tese de doutorado de um dos autores e tem contribuído de forma significativa para a reflexão sobre a construção de um percurso de avaliação crítica e dialética, fugindo de um estereótipo de avaliação prescritiva e "punitiva". O quadro referencial de avaliação e demais elementos apresentados neste artigo não tem intenção de ser fechado ou prescritivo. Pelo contrário, pretende ser um indicativo com exemplos de descritores próprios do objeto de estudo, mas que podem ser adaptados a outros programas de Pós-Graduação em Ensino de Ciências, tanto de formação profissional quanto acadêmica. Nesse sentido, a referencialização aqui apresentada pode servir de inspiração para outros contextos, pois oferece total liberdade aos avaliadores para constituírem o seu quadro próprio, respeitando as peculiaridades e características de seus objetos de estudo.

No âmbito desta proposta, procuramos nos distanciar da construção de um exercício meramente tecnicista de elaboração de instrumentos de coleta de dados, para considerarmos aspectos mais estruturantes e identitários da formação pós-graduada em análise. Vale lembrar que o start do processo se localiza na Proposta Inicial do Curso/CAPES que, de modo geral, definirá a trajetória do programa de pós-graduação, com o compromisso firmado no processo formativo de seus discentes. Ao dar voz, também, aos atores envolvidos na formação (docentes do Programa e egressos dos cursos), procuramos proporcionar um exercício de auto-avaliação em prol da melhoria da qualidade da formação em estudo. Isto evidencia a importância deste referencial, que além da própria auto-avaliação - ou avaliação interna - do Programa de caráter não comparativo, mas intrínseco, permitirá uma monitorização de sua execução em todos os quesitos desejáveis a qualquer tempo e hora. Espera-se que este trabalho sustente a importância da existência de um referencial em processos avaliativos, e oriente a construção de outros referenciais para distintos contextos.

\section{Referências}

Alves, M. P. (2004). Currículo e Avaliação - Uma perspectiva integrada. Porto: Porto.

Barbier, J. M. (1985). A avaliação em formação. Lisboa: Afrontamento.

Cachapuz, A. F. (2011) Investigação em Didáctica das Ciências em Portugal - um balanço crítico. In: S. G. Pimenta, (org.) Didática e Formação de Professores: percursos e perspectivas no Brasil e em Portugal. (6 ed.). São Paulo, SP: Cortez, 231-270.

Cruz, E., Pombo, L., \& Costa, N. (2008). Dez anos (1997-2007) de estudos sobre o impacto de Cursos de Mestrado nas práticas de Professores de Ciências em Portugal. Revista Brasileira de Pesquisa em Educação em Ciências, 8(3), 1-22.

Figari, G. (1996). Avaliar que referencial? Porto: Porto.

Hadji, C. (1994). A Avaliação, regras do jogo: das intenções aos instrumentos. Porto: Porto. 
Horta, J. S. B., \& Moraes, M. C. M. (2005). O sistema CAPES de avaliação da pósgraduação: da área de educação à grande área de ciências humanas. Revista Brasileira de Educação, 30, 95-116.

Melo, M. A. A. (2011). Influência do sistema de avaliação da CAPES na qualidade dos programas de pós-graduação. Dissertação de Mestrado em Educação, Universidade Federal do Rio Grande do Sul, Porto Alegre, RS, Brasil.

Nardi, R. (2005) A área de ensino de Ciências no Brasil: Fatores que determinaram sua constituição e suas características segundos pesquisadores brasileiros. Tese de Livre Docência, Faculdade de Ciências, Universidade Estadual Paulista, Bauru, SP, Brasil.

National Education Research Forum. (2000). The Impact of Educational Research on Policy and Practice, Sub-group of NERF Report. England.

Pombo, L., \& Costa, N. (2009). O professor mestre como facilitador do estabelecimento de articulações entre a investigação educacional e as práticas dos professores. Revista electrónica de Enseñanza de las Ciencias, 8(1), 58-71.

Saorim, R. N. S. O. (2009). O sistema de avaliação da CAPES na visão dos gestores dos programas de pós-graduação da Universidade Federal da Paraíba. Dissertação de Mestrado em Ciência da Informação, Universidade Federal da Paraíba, João Pessoa, PB, Brasil.

Sousa, C. P., \& Macedo, E. (2009). Avaliação da pesquisa em Educação e indicadores de produção bibliográfica: um relato sobre o Qualis Periódicos. Revista de Educação Pública, Cuiabá, 18(37), 255-272.

Spagnolo, F., \& Souza, V. C. (2004). O que mudar na avaliação da CAPES? Revista Brasileira da Pós-Graduação, 1(2), 8-34.

Withers, R. (1995). Quality Assessment: two traditions (a review article). Quality Assessment in Education, 3(2), 39-46.

Yamamoto, O., \& Menandro, P. (2004). A avaliação dos programas de pós-graduação em psicologia. Temas em Psicologia da SBP, 12(1), 82-91. 